\begin{tabular}{c|l|l|l}
$\begin{array}{c}\text { Case Reports in } \\
\text { Oncology }\end{array}$ & $\begin{array}{l}\text { Case Rep Oncol 2010;3:434-438 } \\
\text { DOI: 10.1159/000322726 }\end{array}$ & $\begin{array}{l}\text { Published online: } \\
\text { November 29, 2010 }\end{array}$ & $\begin{array}{l}\text { O 2010 S. Karger AG, Basel } \\
\text { ISSN 1662-6575 } \\
\text { www.karger.com/cro }\end{array}$ \\
\hline
\end{tabular}

This is an Open Access article licensed under the terms of the Creative Commons AttributionNonCommercial-NoDerivs 3.0 License (www.karger.com/OA-license), applicable to the online version of the article only. Distribution for non-commercial purposes only.

\title{
Intracardiac Metastatic Sarcoma
}

\author{
J. Louro ${ }^{a} \quad$ T. Villanueva ${ }^{b} \quad$ J. Freire ${ }^{c}$ M.J. Passos ${ }^{c}$ \\ a Medicine Department, Centro Hospitalar Oeste Norte, Caldas da Rainha, \\ ${ }^{\mathrm{b}}$ Algueirao, Rio de Mouro Health Centre Group, and 'Medical Oncology \\ Department, Instituto Português de Oncologia de Lisboa, Lisbon, Portugal
}

\section{Key Words}

Intracardiac metastatic sarcoma - Cardiac murmur - Severe thrombocytopenia - Tumor resection - Systemic chemotherapy

\begin{abstract}
Even though intracardiac sarcoma metastases are rare, they have been previously reported in the literature. We report the case of a 60 -year-old man who had a synovial sarcoma with metastasis in the right ventricle. These findings were associated with the presence of a new cardiac murmur and severe thrombocytopenia. The treatment with systemic chemotherapy resulted in a normalization of the patient's hematologic profile and in a reduction of the intracardiac mass. The patient subsequently underwent intracardiac tumor resection.
\end{abstract}

\section{Case Report}

A 60-year-old man was admitted to our institution with dyspnea, fatigue and diminishing exercise tolerance, which had begun a week before admission. He also complained of morning facial edema and anorexia.

Twelve months earlier, a biphasic synovial sarcoma of the spermatic cord had been excised. Metastatic evaluation was negative. Nine months after the first surgery, the patient underwent a left inguinal orchiectomy due to a local relapse. Microscopically, a biphasic synovial sarcoma with a maximal diameter of $1.5 \mathrm{~cm}$, vascular invasion and 2-mm deep margins was identified. Testicles and spermatic cord did not present neoplastic tissue.

At admission, physical examination revealed a new murmur and facial edema. The ECG demonstrated normal sinus rhythm. Laboratory investigation was remarkable for the following (reference ranges in parentheses): WBC $14.86 \times 10^{9} / 1\left(7.0-10.0 \times 10^{9} / 1\right)$; platelets $24 \times 10^{9} / 1(150-300 \times$ $\left.10^{9} / 1\right)$; AST $69 \mathrm{U} / \mathrm{l}(<37 \mathrm{U} / \mathrm{l})$; ALT $203 \mathrm{U} / \mathrm{l}(<41 \mathrm{U} / \mathrm{l})$, and GGT $361 \mathrm{U} / \mathrm{l}(12-73 \mathrm{U} / \mathrm{l})$. The physical examination showed no splenomegaly or petechiae. An echo-Doppler evaluation of the inferior limbs excluded deep venous thrombosis, but raised the suspicion of tricuspid insufficiency. The ventilation/perfusion scan indicated a low probability of pulmonary thromboembolism. A CT scan of the thorax revealed an asymmetry in the volume of the right cavities, particularly of the atrium and the right ventricular cavities, and poor filling of the right ventricle that seemed to be due to an intracavitary/intraventricular right mass. This mass filled the lumen in practically its whole diameter, protruding into the right atrium and progressing to the pulmonary artery until its bifurcation (fig. 1). There was no safe evidence of a thromboembolic phenomenon in the remaining pulmonary vasculature. In the lung parenchyma, no evidence of recent or old lesions could be found. 
The transesophageal echocardiogram performed to investigate the new murmur showed a heterogeneous intracardiac mass filling the whole right ventricle and extending to the right atrium (fig. 2). As a result, following events could be observed: a certain degree of compression of the left ventricle; dilatation of the right cavities; mild tricuspid regurgitation; preservation of the left ventricular ejection function (66\%), and dilatation of the inferior vena cava.

A right endomyocardic transjugular percutaneous biopsy was performed. The pathological evaluation showed cardiac metastasis of the synovial sarcoma of the spermatic cord. The myelogram revealed that the three hematopoietic series were conserved and free from neoplastic invasion. A CT of the abdomen and a PET scan showed no evidence of additional outbreaks of disease.

The patient subsequently received one cycle of chemotherapy with adriamycin $\left(75 \mathrm{mg} / \mathrm{m}^{2}\right)$. A repeat transesophageal echocardiogram performed on day 15 of treatment showed a mass reduction (fig. 2). The patient received a total of five chemotherapy courses with adriamycin, administered in 21-day cycles. There was a partial response higher than $70 \%$, documented by the CT scan and MRI of the thorax (fig. 3 ), the echocardiogram and by laboratory tests (normal platelet count), and a favorable evolution of the clinical situation was shown.

Unfortunately, after five months of relapse-free disease, there were signs of disease progression, with hemodynamic repercussions, and the patient subsequently underwent partial intracardiac tumor resection, with palliative intention. After surgery, there was a quick progression of the disease, thus no additional second-line chemotherapy was administered.

\section{Discussion}

Primary cardiac tumors are observed in $0.0017-0.03 \%$ of unselected patients at postmortem evaluation [1,2]. In the study by Murphy et al [3], 77\% of the tumors were primary benign, $14 \%$ were metastatic and $9 \%$ were primary malignant. Myxoma was the most common benign tumor and sarcoma was the most common primary malignant tumor. The most common primary sites of cardiac metastasis were, in order of decreasing frequency, the lung and pleura, lymphoma, breast and esophagus [4]. Although 10-25\% of patients with terminal cancer have cardiac metastasis $[5,6]$, clinical evidence is scarce, and premortem diagnosis is unpredictable.

Intracardiac metastases of sarcomas are rare. Additionally, sarcoma metastasis with valvular involvement, which was the case in our patient, is even more rare. Harting et al. [7] reported a case of sarcoma with metastasis in the right ventricle. The primary tumor was in the left axilla and had been excised 27 months before with aggressive surgical intervention.

Characteristic symptoms of intracardiac tumors include: dyspnea, chest pain, cough, hemoptysis, syncope and right ventricular failure [7, 8]. Echocardiography is the procedure of choice for detecting intracardiac tumors, including the more common metastatic $[9,10]$ as well as primary tumors $[9,11]$.

Thrombocytopenia associated with a large metastatic intracardiac and intracaval mass arising from a sarcoma of the spermatic cord is not common. Fishman et al. [8] reported a case of thrombocytopenia associated with hemolytic anemia in a patient with intracardiac metastasis originating from a testicular teratoma. There was a rapid and sustained normalization of his hematologic profile following mass resection. Vohra et al. [12] also described a patient with an intracardiac teratoma associated with thrombocytopenia and severe hemolytic anemia. This was thought to be due to intravascular consumption which responded only transiently to systemic chemotherapy. 


\begin{tabular}{|c|c|c|c|}
\hline $\begin{array}{l}\text { Case Reports in } \\
\text { Oncolocy }\end{array}$ & $\begin{array}{l}\text { Case Rep Oncol 2010;3:434-438 } \\
\text { DOI: } 10.1159 / 000322726\end{array}$ & \begin{tabular}{|l} 
Published online: \\
November 29, 2010
\end{tabular} & $\begin{array}{l}\text { ( ) } 2010 \text { S. Karger AG, Basel } \\
\text { ISSN } 1662-6575 \\
\text { www.karger.com/cro }\end{array}$ \\
\hline
\end{tabular}

Our patient's platelet count normalized with the start of systemic chemotherapy, which was sustained. Because the clinical situation was extremely serious and there was hemodynamic instability, the oncology team decided to suppress ifosfamide from the chemotherapy regimen. We believe that the ventricular mass adherent to the tricuspid valve created an environment of turbulent flow that was responsible for the destruction of the platelets. This is supported by the refractoriness to corticosteroid therapy and by the improvement of the platelet count with the reduction of the size of the mass.

Although surgical treatment of benign cardiac tumors is often curative, malignant tumors, especially metastatic tumors, present a difficult clinical challenge [7]. Complete surgical resection is indicated for patients with a preoperative Karnofsky performance status of $>80 \%$, minimal extracardiac disease or a deteriorating clinical condition related to cardiac symptoms $[7,13]$. The operative risk and the extent of disease spread must be carefully considered and, as such, surgical treatment was not considered the best initial option in our patient.

A diagnosis of cardiac neoplasm, especially metastatic disease, carries a poor prognosis. Kamiya et al. [14] published a review of 135 patients with malignant cardiac tumors. Only three patients remained alive three years after the surgery. Most of them died within 12 months after the surgery. In secondary tumors, operative intervention is less often carried out than in primary cardiac neoplasms. The perioperative mortality rate of secondary tumors is around $40 \%$.

\section{Conclusion}

Intracardiac metastasis arising from sarcomas seldom occurs. The presence of a new cardiac murmur should alert the physician to the possibility of intracardiac spread. This event can cause severe secondary thrombocytopenia, which is not responsive to empiric therapy with corticosteroids. In oligometastatic sarcomas, and when surgical resection is not possible, chemotherapy is an effective therapeutic approach, capable of providing a hematologic response as well as a reduction in the size of the neoplasm, with subsequent correction of the hemodynamic imbalance. In our patient, surgery was finally possible after the chemotherapy regimen, but did not have a significant impact on the disease evolution. Due to the therapeutic measures imposed, the patient had a survival time higher than one year with a good symptomatic control. 


\begin{tabular}{|c|c|c|c|}
\hline $\begin{array}{c}\text { Case Reports in } \\
\text { Oncolois }\end{array}$ & $\begin{array}{l}\text { Case Rep Oncol 2010;3:434-438 } \\
\text { DOI: } 10.1159 / 000322726\end{array}$ & $\begin{array}{l}\text { Published online: } \\
\text { November 29, } 2010\end{array}$ & \begin{tabular}{|l} 
@ 2010 S. Karger AG, Basel \\
ISSN 1662-6575 \\
www.karger.com/cro
\end{tabular} \\
\hline
\end{tabular}

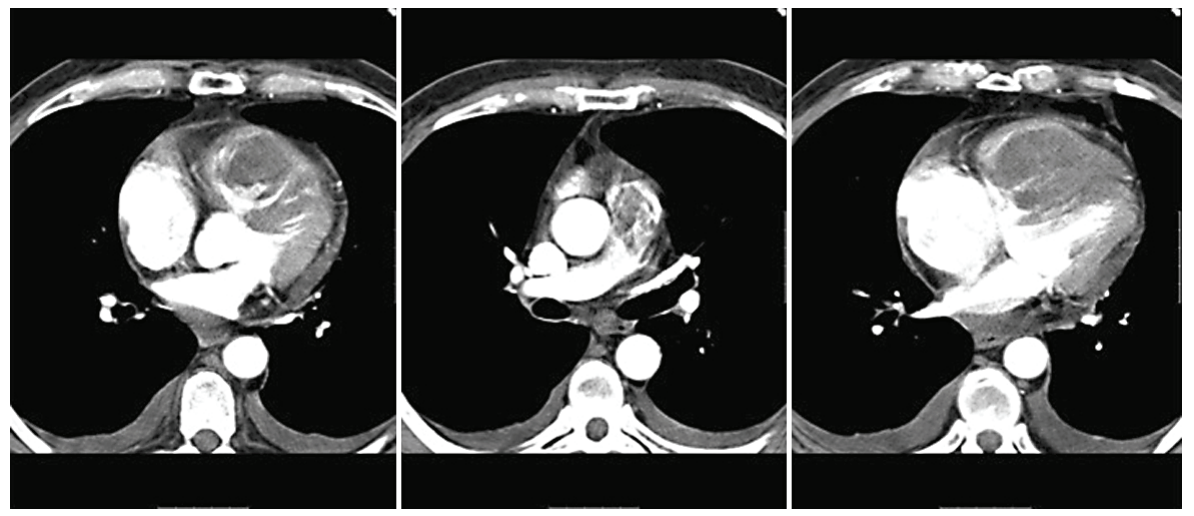

Fig. 1. CT of the thorax before chemotherapy regimen, demonstrating a intracavitary/intraventricular right mass. This mass filled the lumen in practically its whole diameter, protruding into the right atrium and progressing to the pulmonary artery until its bifurcation.
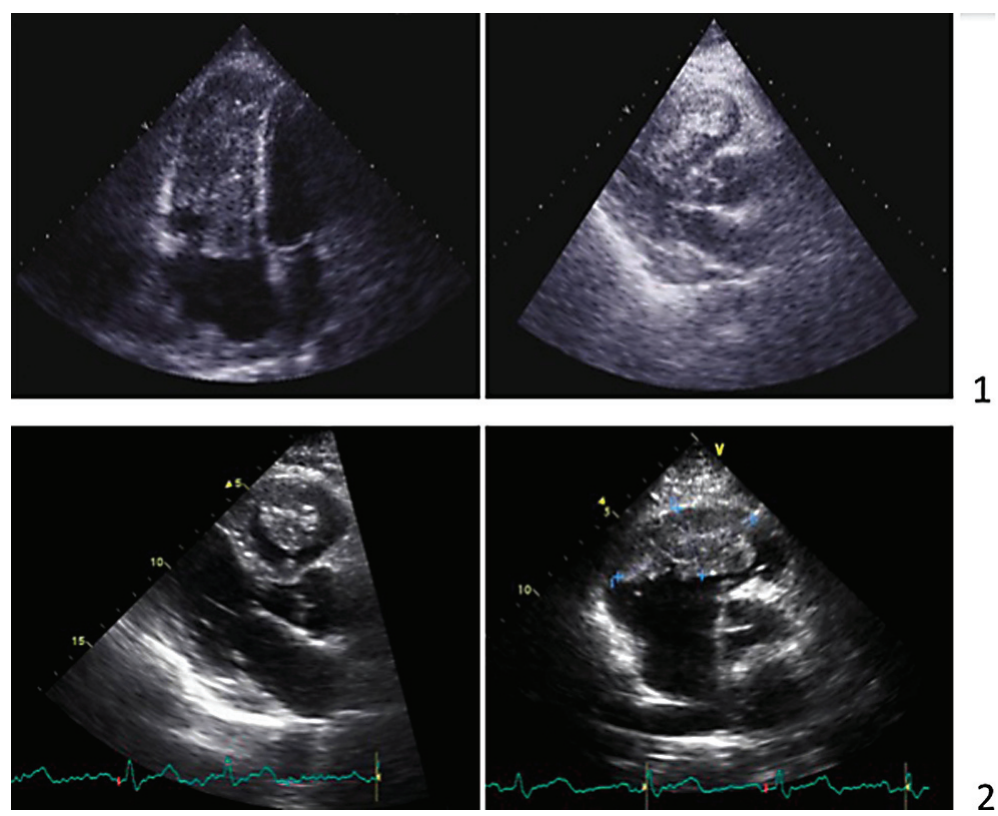

Fig. 2. Transesophageal echocardiogram. (1) Before chemotherapy regimen; a heterogeneous intracardiac mass filling the whole right ventricle and extending to the right atrium can be seen. (2) After chemotherapy regimen; a mass reduction is evident. 


\begin{tabular}{c|l|l|l}
$\begin{array}{c}\text { Case Reports in } \\
\text { OICOlOy) }\end{array}$ & $\begin{array}{l}\text { Case Rep Oncol 2010;3:434-438 } \\
\text { DOI: 10.1159/000322726 }\end{array}$ & $\begin{array}{l}\text { Published online: } \\
\text { November 29, 2010 }\end{array}$ & $\begin{array}{l}\text { ISSN 1662-6575 } \\
\text { ISww.karger.com/cro } \\
\text { www }\end{array}$ \\
\hline
\end{tabular}
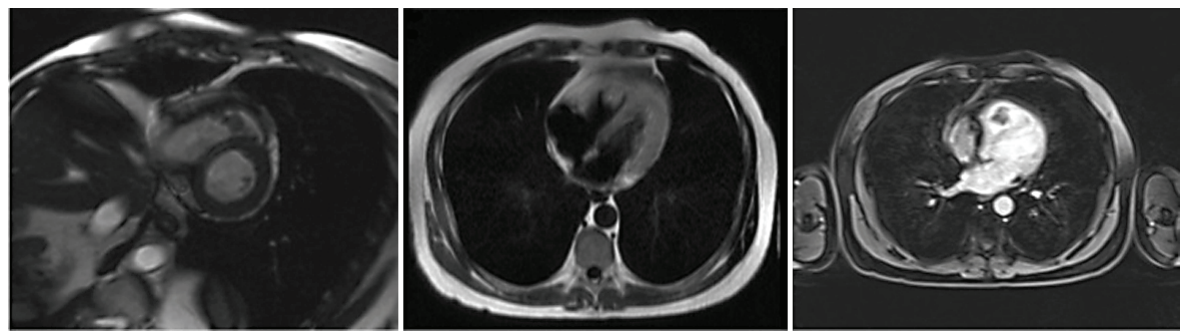

Fig. 3. MRI of the thorax after chemotherapy regimen, demonstrating a significant mass reduction.

\section{References}

1 Straus R, Merliss R: Primary tumor of the heart. Arch Pathol 1945;39:74-78.

2 McAllister HA Jr: Primary tumors and cysts of the heart and pericardium. Curr Probl Cardiol 1979;4:1-51.

-3 Murphy MC, Sweeney MS, Putnam JB Jr, Walker WE, Frazier OH, Ott DA, Cooley DA: Surgical treatment of cardiac tumors: a 25-year experience. Ann Thorac Surg 1990;49:612-617.

4 Klatt EC, Heitz DR: Cardiac metastases. Cancer 1990;65:456-1459.

5 Hanfling SM: Metastic cancer to the heart. Review of the literature and report of 127 cases. Circulation 1960;22:474-483.

6 Lockwood WB, Broghamer WL Jr: The changing prevalence of secondary cardiac neoplasms as related to cancer therapy. Cancer 1980;45:2659-2662.

7 Harting MT, Messner GN, Frazier OH: Sarcoma metastic to the right ventricle: surgical intervention followed by prolonged survival. Tex Heart Inst J 2004;31:93-95.

-8 Fishman AD, Hoffman A, Voltera F, Frymus M, Gentilluci M: Intracaval and intracardiac metastatic nonseminomatous germ cell tumor: a rare case of hemolytic anemia and thrombocytopenia. Cancer Invest 2002;20:996-1001.

\9 Parker M, Russo P, Reuter V, Bosl G, Keefe D: Intracardiac teratoma 15 years after treatment of a nonseminomatous germ cell tumor. J Urol 1993;150:478-480.

10 Kutalek SP, Panidis IP, Kotler MN, Mintz GS, Carver J, Ross JJ: Metastic tumors of the heart detected by twodimensional echocardiography. Am Heart J 1985;109:343-249.

-11 Vargas-Barron J, Romero-Cardenas A, Villegas M, Keirns C, Gomez-Jaume A, Delong R, Malo-Camacho R: Transthoracic and transesophageal echocardiographic diagnosis of myxomas in the four cardiac cavities. Am Heart J 1991;121:931-933.

12 Vohra A, Saiz E, Davila E, et al: Metastatic germ cell tumor to the heart presenting with syncope. Clin Cardiol 1999;22:429-433.

13 Chen R, Gaos C, Frazier OH: Complete resection of a right atrial intracavitary metastatic melanoma. Ann Thorac Surg 1996;61:1255-1257.

14 Kamiya H, Yasuda T, Negamine H, Sakakibara N, Nishida S, Kawasuji M, Watanabe G: Surgical treatment of primary cardiac tumors: 28 years' experience in Kanazawa University Hospital. Jpn Circ J 2001;65:315-319. 